\title{
EMPRESARIALES
}

\section{Devoluciones créditos fiscales. Impuesto al valor agregado. Empresas agroexportadoras. Departamento Itapúa}

\author{
Ninfa Elizabeth Solalinde Díaz , Rosana Rodas
}

\begin{abstract}
Resumen
Introducción: Esta Investigación trata sobre las solicitudes de devoluciones del IVA Crédito Fiscal que las Empresas Agroexportadoras del Departamento de Itapúa presentaron ante la Subsecretaria de Estado de Tributación en los periodos 2014-2016. Se determinan los motivos que impulsan a los agroexportadores a solicitar la devolución de créditos fiscales, además se describen las diferencias que existen entre las devoluciones de créditos en los periodos 2014-2016, también, indagamos la percepción de los profesionales contables del Departamento de Itapúa y por último se determina el nivel de conocimiento de las empresas agroexportadoras acerca de los procesos requeridos para dichas solicitudes de IVA Crédito Fiscal.
\end{abstract}

Objetivo: Analizar las devoluciones de créditos fiscales generadas por el Impuesto al Valor Agregado en las empresas agroexportadoras del Departamento de Itapúa, registradas ante la Subsecretaria de Estado de Tributación en los periodos 2014- 2016.

Material y Método: El tipo de investigación es descriptivo, en razón que se describen las características de las empresas agroexportadoras, contadores y del contexto en general, para luego proceder al análisis de las devoluciones de los créditos fiscales. El diseño es transversal, pues los datos e informaciones se recolectaron en un mismo momento. Se aplicaron encuestas a Directivos de las Empresas Agroexportadoras, como así a los contadores de las mismas.

Resultados: Las empresas agroexportadoras se ven impulsadas a solicitar dichas devoluciones para que de esta manera cumplan sus obligaciones tributarias o puedan comercializar dichos créditos con empresas que la necesita. Algunos de los profesionales no recomiendan someterse al proceso de recupero ya que es bastante tedioso. Los Directivos de las empresas agroexportadoras expresan que la mayoría de las entidades, por desconocer el proceso, no se someten a

1. Universidad Nacional de Itapúa. Facultad de Ciencias Económicas y Administrativas. Carrera de Contaduría Pública.

Trabajo Final de Grado para la obtención del título de Lic. En Contaduría Pública en el año 2018 Fue presentado en la XXVI Jornada de Jóvenes Investigadores de la Asociación de Universidades Grupo Montevideo, realizado del 17 al 19 de octubre en la Universidad Nacional de Cuyo, Mendoza, República Argentina.

E-mail: ninfaelizabeth94@gmail.com

DOI: 10.26885/rcei.foro.2018.90 
ella; pero dan la razón que, al recuperar el crédito éste representa un beneficio económico importante e incentiva a la exportación.

Conclusiones: Las Empresas Agroexportadoras están en su derecho a solicitar el recupero del Impuesto al Valor Agregado Crédito Fiscal, esto se debe a que a lo largo del año haya pagado más IVA del que recibió, pero para ello debe cumplir ciertos requisitos que la Administración Tributaria exige en cuanto a documentos que abalen los créditos. Como bien se sabe que, por las leyes de incentivo de las exportaciones, Paraguay debe devolver el IVA de compras, por ejemplo, el caso de flete, o el caso de fertilizantes y demás insumos para el sector agroexportador.

Palabras clave: créditos fiscales, devolución, agroexportadoras.

\section{Referencias}

Bernal Torres, C. A. (2000). Metodología de la Investigación para Administración y Economía. Colombia: Nomos S.A.

Kretschmer, E. L. (2012). Impacto económico-financiero de los procesos tributarios de recuperación del Impuesto al Valor Agregado en empresas exportadoras, comerciales e industriales, del Departamento de Itapúa. Encarnación, Paraguay.

LEY $N^{\circ}$ 125/91, Que establece el nuevo Régimen Tributario y sus modificaciones.

Ruoti, N. (2011). Lecciones para Cátedra de Derecho Tributario. Asunción: AGR Servicios Gráficos S.A.

SET. (2016). Res. Gral. No 89/16. Obtenido de Subsecretaría de Estado de Tributación. Recuperado de http://www.set.gov.py/portal/PARAGUAYSET/detail?folder-id=repository:collaboration:/sites/PARAGUAY-SET/ categories/SET/Normativas/resoluciones/2016 